\title{
Case Report: Effect of Therapeutic Pulsed Ultrasound on Smell Dysfunction: A Case Study
}

\author{
Atieh Nazem ${ }^{1}\left(\mathbb{D}\right.$, Sofia Naghdi', Noureddin Nakhostin Ansari ${ }^{1 *}\left(\mathbb{1}\right.$, Mojtaba Fathali $^{1}$
}

1. Department of Physiotherapy, School of Rehabilitation, Tehran University of Medical Sciences, Tehran, Iran.

Citation: Nazem A, Naghdi S, Nakhostin Ansari N, Fathali M. Effect of Therapeutic Pulsed Ultrasound on Smell Dysfunction: A Case Study. Journal of Modern Rehabilitation. 2018; 12(1):71-76. http://dx.doi.org/10.32598/jmr.12.1.71

http://dx.doi.org/10.32598/jmr.12.1.71

Funding: See Page 75

(c) Copyright: The Author(s)

Article info:

Received: 13 Jul 2017

Accepted: 27 Nov 2017

Available Online: 01 Jan 2018

\section{Keywords:}

Smell dysfunction, Ultrasound, Therapeutic pulsed ultrasound, Sinusitis

\begin{abstract}
Introduction: Olfactory dysfunction is one of the main symptoms of Chronic Rhinosinusitis (CRS) caused by bacteria in the form of biofilm. Therapeutic Pulsed Ultrasound (TPU), besides its anti-inflammatory effects has the ability to disintegrate the strong walls of biofilms (community of bacteria), thus help relieve the symptoms of CRS, one of the major symptoms of which is olfactory dysfunction.

Case Description: A 42-year-old man with CRS whose olfactory sense had gradually declined over two years, underwent TPU for ten sessions (three days a week) on his maxillary and frontal sinuses. Findings of CT scan and the Sino-Nasal Outcome Test (SNOT-20) questionnaire were employed to assess the severity of the symptoms. Moreover, the Iran Smell Identification Test (Iran-SIT) was used to measure the degree of olfactory dysfunction. Smell dysfunction and the severity of symptom in CRS relatively improved according to SNOT-20 and ISIT scales by $80 \%$ and $41 \%$, respectively. It appears that TPU can improve the olfactory dysfunction and other symptoms caused by CRS.
\end{abstract}

\section{Introduction}

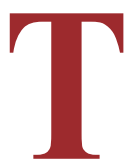

he sense of smell is one of the important senses to ensure our safety (making us conscious of the environment), assist in the perception of tastes, increase sexual power, and manage time and place [1]. Olfactory dysfunction decreases life quality and ultimately leads to social inefficiency and depression [2]. There are various causes of olfactory dysfunction, one of which is Chronic Rhinosinusitis (CRS) [3]. CRS is one of the ten most common diseases around the world and inflicts approximately 12.5 million people in Europe and the USA each year [3]

CRS has two types of symptoms: major symptoms and minor symptoms. Olfactory dysfunction is a major symptom. Approximately $65 \%$ to $85 \%$ of people contracting CRS experience olfactory dysfunction [3]. The stronger the CRS condition, the greater the degree of olfactory dysfunction [4]. The most repetitive cause of contracting CRS is the biofilm form of bacteria [3]. Biofilm is remarkably resistant to body's immune system and antibiotics [4]

* Corresponding Author: 
The inflammation caused by the bacteria in the mucus of the sinuses and the nose prevents the olfactory molecules from reaching the surface layer of the epithelium. In addition, the edema caused by the inflammation will result in olfactory nerve synapses disorder, which in turn, disrupts the transmission of the olfactory messages [5]. Common treatments that help recover from CRS include antibiotics, steroids, and saline [6].

Different factors such as the resistance of biofilm bacteria to common treatments [7], failure of the treatments [8], as well as side effects of using steroids (such as stomach ulcers, osteoporosis, and immune system deficiency) have all cast doubt on the use of common treatments [4]. Studies conducted on the effects of continuous and Therapeutic Pulsed Ultrasound (TPU) indicate acceptable findings on the alleviation of symptoms and improvement of smell sense [9-14].

\section{Case Description}

Our study case was a 42-year-old man, who had suffered from CRS, diagnosed by a specialist and based on CT scan findings. The chief complaint in CRS is olfactory dysfunction. Moreover, he had problem in tasting because smell dysfunction affects the sense of taste, too [1]. Thus, he couldn't feel the taste or smell of food. Because of losing his appetite and passion for eating, he had lost about $5 \mathrm{~kg}$ weight.

During his illness, the patient used various drugs such as antibiotics, nasal saline, and oral steroids to alleviate his symptoms. However, the recurrence and persistence of olfactory dysfunction and other symptoms of CRS showed the failure of these common medications. CRS was diagnosed by an ENT specialist and based on CT scan clinical findings. The patient was referred to a physiotherapy clinic. During treatment the patient did not use any drugs and spray. CT scan findings were rated from 0 (clean), 1 (mild), 2 (moderate), and 3 (total obscurity) by the specialist physician $[15,16]$ before and after the treatment (Table 1).

The severity of the symptoms of chronic sinusitis was determined by the valid questionnaire of Sino-Nasal Outcome Test (SNOT-20) [17] (from 0: No symptom to
5: The most intense symptom) (Table 2). In addition, olfactory sense involvement was rated by the Persian version of the University of Pennsylvania's Smell Identification Test (SIT) known as Iran-SIT (from 0 to 24) [18, 19]. Table 3 presents the identification of odors by the patient in the first therapy session, the last therapy session, and one month after the last therapy session.

The therapeutic goals in this study included the improvement of olfactory sense caused by CRS and the alleviation of other symptoms of chronic rhinosinusitis, such as the post-nasal drip, headache, ear fullness, fatigue, and the clarity of the maxillary sinuses in the clinical findings. The ultrasound device employed was an ITO US-750. The applicator surface was $1 \mathrm{~cm}^{2}$, ERA (Effective Radiation Area) was $0.9 \mathrm{~cm}^{2}$, and the beam non-uniformity ratio was 3.6 (that is very low). For each maxillary sinus, the physiotherapist applied $1 \mathrm{w} / \mathrm{cm}^{2}$ for 5 minutes, also he applied 10\% pulsed ultrasound in the site of the surface anatomy of the maxillary and frontal sinuses for 10 sessions ( 3 sessions a week).

The valid Persian version of the Sino-Nasal Outcome Test (SNOT-20) was employed in order to analyze the intensity of the symptoms. In this questionnaire, 15 questions were allocated to symptoms such as sneezing, coughs, need to empty the nose, etc. and 5 questions to life quality and psychological effects of the disease such as a decline in focus, desperation, and fatigue. The severity of symptoms was rated from 0 to 5 (0: No problem, 1: Few problems, 2: Some problems, 3: Moderately problematic, 4: Intensely problematic, 5: Very intensely problematic).

The sum of scores was 100 showing "the problem as bad as it can be" and 0 representing "no problem". The validity and reliability of SNOT-20 have been already approved. The SNOT-20 score before our treatment, after treatment, and 1-month follow-up was 24, 3, and 2, respectively (Table 1 ). The extent of the olfactory dysfunction was evaluated before the treatment, after the treatment, and one month after the last session of the therapy, using the Persian version of Pennsylvania SIT.

In this test, 24 different aromas were used and on the basis of the scores, olfactory dysfunction was rated from

Table 1. The patient's scores of snot-20 in pre/post and fallow up

\begin{tabular}{cccc}
\hline SNOT-20 & Before & After (10 Sessions) & 1-Month Follow-Up \\
\hline Scores & 24 & 3 & 2 \\
\hline
\end{tabular}


Table 2. Sino-Nasal Outcome Test

\begin{tabular}{|c|c|c|c|c|c|c|}
\hline Symptoms of CRS & No Problem & Very Mild & Mild & Moderate & Severe & $\begin{array}{l}\text { As Bad As } \\
\text { It Can Be }\end{array}$ \\
\hline 1. Need to blow nose moderate (4) & 0 & 1 & 2 & 3 & 4 & 5 \\
\hline 2. Sneezing mild (3) & 0 & 1 & 2 & 3 & 4 & 5 \\
\hline 3. Runny nose as bad as it can be (5) & 0 & 1 & 2 & 3 & 4 & 5 \\
\hline 4. Cough as bad as it can be (5) & 0 & 1 & 2 & 3 & 4 & 5 \\
\hline 5. Post-nasal discharge severe (4) & 0 & 1 & 2 & 3 & 4 & 5 \\
\hline 6. Thick nasal discharge severe (4) & 0 & 1 & 2 & 3 & 4 & 5 \\
\hline 7. Ear fullness moderate (3) & 0 & 1 & 2 & 3 & 4 & 5 \\
\hline 8. Dizziness very mild (1) & 0 & 1 & 2 & 3 & 4 & 5 \\
\hline 9. Ear pain very mild (1) & 0 & 1 & 2 & 3 & 4 & 5 \\
\hline 10. Facial pain/pressure severe (4) & 0 & 1 & 2 & 3 & 4 & 5 \\
\hline 11. Difficulty in falling asleep as bad as it can be (5) & 0 & 1 & 2 & 3 & 4 & 5 \\
\hline 12. Wake up at night as bad as it can be (5) & 0 & 1 & 2 & 3 & 4 & 5 \\
\hline 13. Lack of a good night's sleep as bad as it can be (5) & 0 & 1 & 2 & 3 & 4 & 5 \\
\hline 14. Wake up tired severe (4) & 0 & 1 & 2 & 3 & 4 & 5 \\
\hline 15. Fatigue moderate (3) & 0 & 1 & 2 & 3 & 4 & 5 \\
\hline 16. Reduced productivity moderate (3) & 0 & 1 & 2 & 3 & 4 & 5 \\
\hline 17. Reduced concentration severe (4) & & 1 & 2 & 3 & 4 & 5 \\
\hline 18. Frustrated/ restless/ irritable severe (4) & 0 & 1 & 2 & 3 & 4 & 5 \\
\hline 19. Sad severe (4) & 0 & 1 & 2 & 3 & 4 & 5 \\
\hline 20. Embarrassed severe (4) & 0 & 1 & 2 & 3 & 4 & 5 \\
\hline
\end{tabular}

$J \mathrm{MR}$

0-7: Anosmia (loss of olfactory sense), 8-13: Severe hyposmia (decrease in smell sense), 14-19: Mild hyposmia, and 19-24: Normosmia (normal smell sense). The patient selected the closest smell among accessible choices at the bottom of every sticker and then based on the scores received; the severity of olfaction dysfunction was recognized in the range of normosmia to anosmia. The patient's score was 13 and was classified under the 'severe hyposmia' class. After 10 sessions of intervention, his score reached 24 , showing an improvement in smell dysfunction (Table 4).

\section{Discussion}

Olfactory dysfunction caused by chronic rhinosinusitis is the result of inflammation and the subsequent edema. This condition may lead to the interruption of smell messages [12] and dysfunction of synaptic spaces. Considering the anti-inflammation effects of TPU and according to recent studies $[12,14,16]$, therapeutic ultrasound can influence the symptoms of CRS and its resulting smell dysfunction. Because of the high prevalence of olfactory dysfunction in CRS, limited effects 
Table 3. The patient's Iran Smell Identification Test (Iran-IST) results

\begin{tabular}{|c|c|c|}
\hline Number & Odors of ISIT & Identification Odors by Patient \\
\hline 1 & Banana & True \\
\hline 2 & Rose water & True \\
\hline 3 & Garlic & False \\
\hline 4 & Mint & False \\
\hline 5 & Hami melon & False \\
\hline 6 & Cologne & False \\
\hline 7 & Cinnamon & True \\
\hline 8 & Coconut & True \\
\hline 9 & Peach & True \\
\hline 10 & Chocolate & False \\
\hline 11 & Bubble gum & True \\
\hline 12 & Pineapple & False \\
\hline 13 & Grape & True \\
\hline 14 & Onion & True \\
\hline 15 & Smoke & True \\
\hline 16 & Biscuit & False \\
\hline 17 & Peanut & False \\
\hline 18 & Cola & True \\
\hline 19 & Watermelon & False \\
\hline 20 & Apple & True \\
\hline 21 & Dried lime & False \\
\hline 22 & Strawberry & True \\
\hline 23 & Soap & True \\
\hline 24 & Jasmine & False \\
\hline
\end{tabular}

of common therapeutic methods, and possibility of the recurrence of symptoms after taking medications, there is an urgent need for an alternative treatment.

Table 4. The patient's scores of ISIT in pre/post and fallow up
It appears that TPU can significantly affect the symptoms of CRS for the following reasons: 1 . TPU has antiinflammation effects against bacterial inflammation, and altering the cell membrane permeability leads to the re-

\begin{tabular}{cccc}
\hline ISIT & Before & After (10 Sessions) & 1-Month Follow-Up \\
\hline Scores & 13 & 24 & 24
\end{tabular}


generation of the tissue $[4,5]$; and 2. TPU mechanical effects separates sticky secretions from the sinuses and facilitate emptying and drainage [5].

The effects of TPU modality have not been specifically and objectively applied to olfactory dysfunction. In this study, olfactory dysfunction and its severity were evaluated using native and valid tests. It appears that non-invasive TPU can significantly treat olfactory dysfunction and other symptoms of CRS. This case study with a 1-month follow-up showed that pulsed ultrasound can be effective in improving olfactory dysfunction and other symptoms of chronic sinusitis. The maxillary sinuses were improved, as confirmed by clinical findings and symptoms. Future studies can further shed light on this therapeutic intervention.

Limitations should be acknowledge. Control group could be added to research design for accurate assessment of therapeutic ultrasound. Although the sample size should be more than this study to reared carefully and ample of characters diffidence between patients.

\section{Ethical Considerations}

\section{Compliance with ethical guidelines}

This study has been approved by the Ethics Committee of Tehran University of Medical Sciences (Code: IR.TUMS.FNM.REC.1396.2079).

\section{Funding}

This study has been financially supported by Tehran university of Medical Sciences.

\section{Conflict of interest}

The authors declare no conflict of interest.

\section{References}

[1] Holbrook EH, Leopold DA. An updated review of clinical olfaction. Current Opinion in Otolaryngology \& Head and Neck Surgery. 2006; 14(1):23-8. [DOI:10.1097/01. moo.0000193174.77321.39] [PMID]

[2] Croy I, Hummel T. Olfaction as a marker for depression. Journal of Neurology. 2017; 264(4):631-8. [DOI:10.1007/ s00415-016-8227-8] [PMID]
[3] Gaines AD. Anosmia and hyposmia. Allergy and Asthma Proceedings. 2010; 31(3):185-9. [DOI:10.2500/ aap.2010.31.3357] [PMID]

[4] Costerton JW, Stewart PS, Greenberg EP. Bacterial biofilms: A common cause of persistent infections. Science. 1999; 284(5418):1318-22. [DOI:10.1126/science.284.5418.1318] [PMID]

[5] Dunne WM. Bacterial adhesion: Seen any good biofilms lately? Clinical Microbiology Reviews. 2002; 15(2):155-66. [DOI:10.1128/CMR.15.2.155-166.2002] [PMID] [PMCID]

[6] Gupta D, Gulati A, Singh I, Tekur U. Endoscopic, radiologi$\mathrm{cal}$, and symptom correlation of olfactory dysfunction in preand postsurgical patients of chronic rhinosinusitis. Chemical Senses. 2014; 38(8):705-10. [DOI:10.1093/chemse/bju042] [PMID]

[7] Jafek BW, Moran DT, Eller PM, Rowley JC, Jafek TB. Steroiddependent anosmia. Laryngoscope. 1987; 111(2):200-3. [DOI: 10.1097/00005537-200102000-00002] [PMID]

[8] Raviv JR, Kern RC. Chronic sinusitis and olfactory dysfunction. Otolaryngologic Clinics of North America. 2004 37(6):1143-57. [DOI:10.1016/j.otc.2004.06.003] [PMID]

[9] Bendouah Z, Barbeau J, Hamad WA, Desrosiers M. Biofilm formation by Staphylococcus aureus and Pseudomonas aeruginosa is associated with an unfavorable evolution after surgery for chronic sinusitis and nasal polyposis. OtolaryngolHead and Neck Surgery. 2006; 134(6):991-6. [DOI:10.1016/j. otohns.2006.03.001] [PMID]

[10] Ansari NN, Naghdi S, Farhadi M, Jalaie S. A preliminary study into the effect of low-intensity pulsed ultrasound on chronic maxillary and frontal sinusitis. Physiotherapy Theory and Practice. 2007; 23(4):211-8. [DOI:10.1080/09593980701209360] [PMID]

[11] Stanbury RM, Graham EM. Systemic corticosteroid therapy-side effects and their management. British Journal of Ophthalmology. 1998; 82(6):704-8. [PMID] [PMCID]

[12] Young D, Morton R, Bartley J. Therapeutic ultrasound as treatment for chronic rhinosinusitis: Preliminary observations. Journal of Laryngol Ortology. 2010; 124(5):495-99. [DOI:10.1017/S0022215109992519]

[13] Ansari NN, Naghdi S, Farhadi M. Physiotherapy for chronic rhinosinusitis: The use of continuous ultrasound. International Journal of Physical Therapy \& Rehabilitation. 2013, 14(7):306-10. [doi:10.12968/ijtr.2007.14.7.23837]

[14] Bartley J, Young D. Ultrasound as a treatment for chronic rhinosinusitis. Medical Hypotheses. 2009; 73(1):15-7. [DOI:10.1016/j.mehy.2008.12.049]

[15] Naghdi S, Ansari NN, Farhadi M. A clinical trial on the treatment of chronic rhinosinusitis with continuous ultrasound. Journal of Physical Therapy Science. 2008; 20(4):233-8. [DOI:10.1589/jpts.20.233]

[16] Ansari Fathali M, Naghdi S, Hasson S. Effect of pulsed ultrasound on chronic rhinosinusitis: A case report Physiotherapy Theory and Practice. 2010; 26(8):558-63. [DOI:10.3109/09593981003628153 ][PMID]

[17] Ansari NN, Naghdi S, Farhadi M. Therapeutic ultrasound as a treatment for chronic sinusitis. Physiotherapy Research International. 2004; 9(3):144-6. [doi:10.1002/pri.315] 
[18] Ansari NN, Fathali M, Naghdi S, Hasson S. Effect of pulsed ultrasound on chronic rhinosinusitis: A case report. Physiotherapy Theory and Practice. 2010; 26(8):558-63. [DOI:10.3109/09593981003628153]

[19] Taherkhani S, Moztarzadeh F, Mehdizadeh Seraj J, Hashemi Nazari SS, Taherkhani F, Gharehdaghi J, et al. Iran Smell Identification Test (Iran-SIT): A modified version of the University of Pennsylvania Smell Identification Test (UPSIT) for Iranian population. Chemosensory Perception. 2015; 8(4):18391. [DOI:10.1007/s12078-015-9192-9] 